Robert E. Hermes, ${ }^{1}$ Lorene S. Valdez-Boyle, ${ }^{2}$ Joseph F. Stampfer, 3

and David R. Ramsey 4

\title{
PROTECTIVE MATERIALS WITH REAL-TIME PUNCTURE DETECTION CAPABILITY
}

REFERENCE: Hermes, R. E., Valdez-Boyle, L. S., Stampfer, J. F., Ramsey, D. R., "Protective Materials with Real-Time Puncture Detection Capability", Performance of Protective Clothing: 6th Volume ASTM STP 1273, Jeffrey O. Stull and Arthur D. Schwope, Eds., American Society for Testing and Materials, Philadelphia, 1997.

ABSTRACT: The protection of workers from chemical, biological, or radiological hazards requires the use of protective materials that can maintain their integrity during use. An accidental puncture in the protective material can result in a significant exposure to the worker. A five ply material has been developed that incorporates two layers of an electrically conductive polymer sandwiched between three layers of a nonconductive polymer. A normally open circuit that is connected between the conductive layers will be closed by puncturing the material with either a conductive or nonconductive object. This can be used to activate an audible alarm or visual beacon to warn the worker of a breach in the integrity of the material. The worker is not connected to the circuit, and the puncture can be detected in real-time, even when caused by a nonconductor.

KEYWORDS: puncture detection, protective materials, electrical conductivity

The Los Alamos National Laboratory and other nuclear facilities controlled by the Department of Energy use a variety of administrative and physical controls to reduce the radiological exposure of their workers to as low as reasonably achievable (ALARA).

1Technical Staff Member, Materials Science and Technology Division, Group

MST-7, Mail Stop E549, Los Alamos National Laboratory, Los Alamos, NM 87545.

${ }^{2}$ Current address: Medical Student, University of New Mexico School of Medicine, Albuquerque, NM 87131.

3 Guest Scientist, Environmental, Safety, and Health Division, Group EŞH-5, Mail Stop K553, Los Alamos National Laboratory, Los Alamos, NM 87545.

${ }^{4}$ Current adaress: Principal Architect, Paradigm Systems Corporation, 1918 110th Place N.E., Bellevue, WA 98004. 


\section{DISCLAIMER}
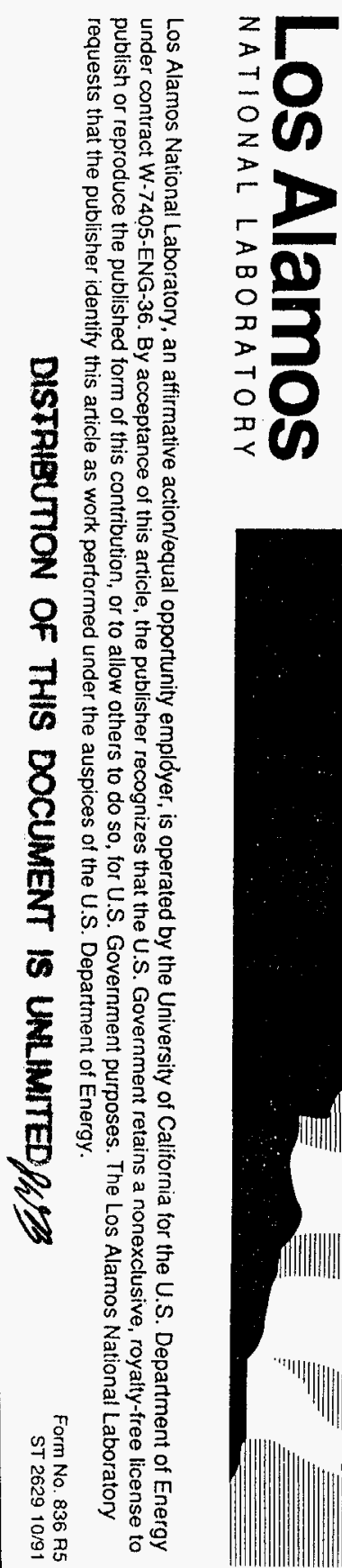

This report was prepared as an account of work sponsored by an agency of the United States Government. Neither the United States Government nor any agency thereof, nor any of their employees, makes any warranty, express or implied, or assumes any legal liability or responsibility for the accuracy, completeness, or usefulness of any information, apparatus, product, or process disclosed, or represents that its use would not infringe privately owned rights. Reference herein to any specific commercial product, process, or service by trade name, trademark, manufacturer, or otherwise does not necessarily constitute or imply its endorsement, recommendation, or favoring by the United States Government or any agency thereof. The views and opinions of authors expressed herein do not necessarily state or reflect those of the United States Government or any agency thereof.

C

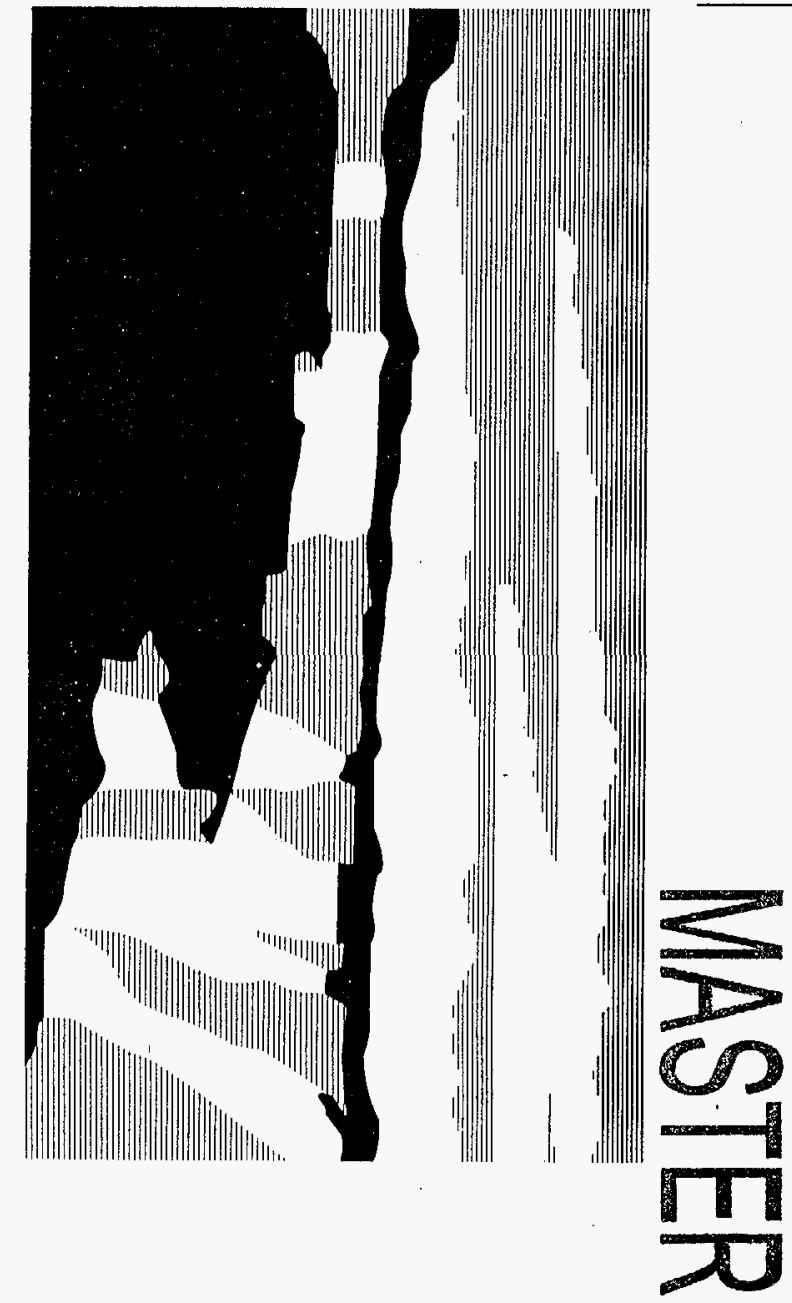

$\frac{5}{1}$

10

6

Q

0

G

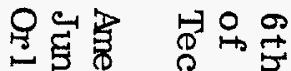

胥胥

包

\&

웅

$\omega^{\circ}$

0 त

国6

的苔索

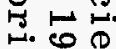

कृष्य

옹

क 总留

象 品㝵

苛 四苛

品

可

可

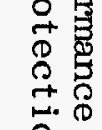

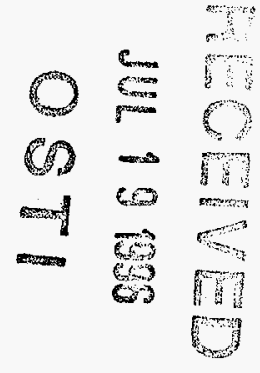




\section{DISCLAIMER}

Portions of this document may be illegible in electronic image products. Images are produced from the best available original document. 


\section{ASTM.PMR-TPDC.V2:}

Robert E. Hermes, ${ }^{1}$ Lorene S. Valdez-Boyle, ${ }^{2}$ Joseph F. Stampfer, ${ }^{3}$

and David R. Ramsey 4

\section{PROTECTIVE MATERIALS WITH REAL-TIME PUNCTURE DETECTION CAPABILITY}

REFERENCE: Hermes, R. E., Valdez-Boyle, L. S., Stampfer, J. F., Ramsey, D. R., "Protective Materials with Real-Time Puncture Detection Capability", Performance of Protective Clothing: 6th Volume ASTM STP 1273, Jeffrey O. Stull and Arthur D. Schwope, Eds., American Society for Testing and Materials, Philadelphia, 1997.

ABSTRACT: The protection of workers from chemical, biological, or radiological hazards requires the use of protective materials that can maintain their integrity during use. An accidental puncture in the protective material can result in a significant exposure to the worker. A five ply material has been developed that incorporates two layers of an electrically conductive polymer sandwiched between three layers of a nonconductive polymer. A normally open circuit that is connected between the conductive layers will be closed by puncturing the material with either a conductive or nonconductive object. This can be used to activate an audible alarm or visual beacon to warn the worker of a breach in the integrity of the material. The worker is not connected to the circuit, and the puncture can be detected in real-time, even when caused by a nonconductor.

KEYWORDS: puncture detection, protective materials, electrical conductivity

The Los Alamos National Laboratory and other nuclear facilities controlled by the Department of Energy use a variety of administrative and physical controls to reduce the radiological exposure of their workers to as low as reasonably achievable (ALARA).

${ }_{1}$ Technical Staff Member, Materials Science and Technology Division, Group MST-7, Mail Stop E549, Los Alamos National Laboratory, Los Alamos, NM 87545.

${ }^{2}$ Current address: Medical Student, University of New Mexico School of Medicine, Albuquerque, NM 87131.

3 Guest Scientist, Environmental, Safety, and Health Division, Group ESH-5, Mail Stop K553, Los Alamos National Laboratory, Los Alamos, NM 87545.

${ }^{4}$ Current address: Principal Architect, Paradigm Systems Corporation, 1018 110th Place N.E., Bellevue, WA 98004. 
In practice, Los Alamos uses negative pressure gloveboxes in order to protect workers from radioactive operations that may lead to significant exposure if performed without such protection. The radiological gloveboxes are fitted with three ply gloves consisting of a central layer of lead oxide filled polychloroprene, with external layers of chlorosulfonated polyethylene. The lead oxide filler is designed to reduce the penetration of radiation through the glove. The total thickness is approximately 30 mils $(0.076 \mathrm{~cm})$.

Various administrative controls have been implemented in order to help reduce radioactive contamination of workers. Radiation protection personnel regularly inspect the gloves for holes using both visual and radiological evaluations, but physical punctures and pinholes that develop during use are the primary means of worker exposure. Radiological workers are required to monitor their hands after each use of the glovebox gloves in order to prevent contamination from spreading to other units and/or personnel. Therefore, the contamination is only discovered well after the exposure has occured, from several minutes to a couple of hours . Personnel associated with the safety aspects of these operations recognized the need for a glove design which could detect punctures while they are in use. A cost/benefit analysis, which included the use of such a glove in Los Alamos' radiological operations, projected a savings of up to $\$ 500,000$ per year.

In the last several years, many methods have been developed for testing the integrity of gloves in the health care industry, some of which depend upon the use of an electronic means to detect a pinhole or other breach in the glove. The tests are based upon methods used by manufacturers of condoms and linemans gloves where a voltage is applied accross the material while it is filled with, and then immersed in, a conducting electrolyte (usually saline solutions). A hole is detected by the completion of the normally open circuit. A glove worn by a health professional can be checked by immersing the gloved hand into a conducting electrolyte that is connected in series to a direct current alarm which is then connected to a conducting clip located on the individual [1,2]. A pinhole or cut allows the electrolyte to come in contact with the person's hand, which in turn, completes the circuit, sounding an alarm. A similar method uses electrodes connected to a faucet that requires the user to be connected simultaneously in series while rinsing the gloved hand under the flowing water [ $\underline{3}]$. Other methods actually provide a means for the patient and health care worker to be joined by an electical circuit that sounds an alarm if electrical contact is made from bodily fluids passing through a breach in the glove [4,5]. These methods were found to be unsuitable due to the difficulty of checking glovebox gloves that, under normal operating conditions, are extended inside the glovebox.

Another design, which we found more appropriate for our use, was a three ply material having either an insulating layer sandwiched between two electrically conductive layers, or the conducting layer between two insulating layers [6]. However, this system could only detect breaches which occur where the material was punctured by an electrically conducting device, such as a scalpel.

Although the major portion of punctures may, in fact, be caused by sharp metal objects, a significant amount are caused by sharp nonconductors such as wood splinters and glass shards. The goal of our research was to develop a material that would work for all cases of punctures, as well as be general enough to work with any protective material, be it a glove, garment, full body suit, or disposal bag.

We report here the development of a multilayered material which does not require electrical contact with the user, and because of the nature of the material used in the conductive layers, even works when punctured by a nonconductive material [7]. 


\section{EXPERIMENTAL METHOD}

\section{Preparation of Multiple Layered Test Specimens}

Materials--Chlorosulfonated polyethylene and lead-loaded polychloroprene were obtained as solutions in a mixture of toluene and xylene(s) direct from the manufacturer who makes the lead-loaded glovebox gloves [8]. Polyvinylalcohol ( $99 \%$ hydrolysed), reagent grade glycerol, and reagent grade sodium chloride were obtained from Baker Chemical Co., and used as received. Deionized water was used as the solvent for preparing the electrolyte.

Electrolyte--The polyelectrolyte was prepared from an aqueous solution containing $2 \%$ sodium chloride, $4 \%$ glycerol, and $5 \%$ polyvinylalcohol.

Test Specimens--Several of these were prepared by a sequential cast method. The first layer consisted of a 2.8 inch $(7 \mathrm{~cm})$ diameter circular film of chlorosulfonated polyethylene which was cast on a glass substrate, and left in a fume hood to remove the solvent overnight. The second layer, the polyelectrolyte, was cast over the first layer with a diameter of 2.0 inches $(5 \mathrm{~cm})$, and included two wire electrodes which were separated by 1.4 inches $(3.6 \mathrm{~cm})$ and extended well beyond the diameter of the first layer. After air drying overnight the polyelectrolyte was a solid material which was highly plasticized by the glycerol. A third layer composed of lead-loaded polychloroprene was cast with a diameter of 2.4 inches $(6 \mathrm{~cm})$, again with solvent removal overnight. The fourth layer was cast with the polyelectrolyte and wire electrodes, similar to the second layer. The fifth and final layer was cast with chlorosulfonated polyethylene, similar to the first layer. After drying was complete, the thickness of each layer was $10,10,20,15$, and 5 mils $(0.025,0.025,0.050,0.038$, and $0.012 \mathrm{~cm})$ respectively. The samples were pealed from the substrate, and kept at ambient conditions prior to testing.

\section{Puncture Test Procedure}

The polyelectrolyte layers in the test specimens were measured for resistance by simply attaching the wire electrodes to a digital multimeter. The resistivity of the conductive layers in freshly prepared test specimens ranged from 12 to 14 megohms. The resistivity between the two conductive layers ( 2 and 4$)$ was infinite, indicating no contact between the two layers. Samples that were aged for 11 months prior to puncture testing had an increase in the resistivity of the conductive layers to a still measurable range between 28 and 30 megohms.

Metal Pin Test--While monitoring the resistivity between layers 2 and4, a tapered, semiblunt pushpin with a nominal diameter of 47 mils $(0.12 \mathrm{~cm})$ was inserted into the material, perpendicular to the plane of the test specimen.

Sharp Wooden Dowel Test--Similarly, a splintered dowel with a nominal diameter of 85 mils $(0.21 \mathrm{~cm})$ was inserted into the material being tested, perpendicular to the plane of the test specimen. 


\section{RESULTS and DISSCUSION}

In the fresh samples prepared in the manner described above, the electrical resistance between layers 2 and 4 , which prior to the metal pin puncture had been infinite, immediately fell to an average reading of 13 megohms, indicating a connection between the two conductive layers, and a breach in the material. The results of three specimens were similar. Only one test could be completed with each specimen because a puncture resulted in a permanent connection between the conductive layers. A punctured sample which had aged for 11 months (with pushpin removed) still displayed a resistance of 30 megohms. This demonstrated the fact that the conductive electrolyte from layer 4 must have been carried through layer 3 in order to contact layer 2 and was a permanent connection, at least to the limit of the test.

An 11 month aged sample was then tested with the metal pushpin, and the resistivity immediately fell to 38 megohms, again indicating contact and a breach in the integrity of the specimen. An 11 month aged sample was also tested with a splintered wooden dowel, and the resistivity immediately dropped to $35 \mathrm{megohms}$, indicating contact between the conductive layers. Therefore, using this nonconductive object to pierce the test specimen resulted in a portion of one layer being carried through to make contact with the other layer. Piercing with a glass object was not attempted.

\section{CONCLUSION}

We have demonstrated that a multilayered material can be made having the desirable characteristic of real-time puncture detection, even with nonconductive piercing objects. Los Alamos National Laboratory, operated by the University of California for the Department of Energy, has currently subcontracted a glove manufacturer to make prototype gloves using an improved version of what was disclosed here.

\section{REFERENCES}

[1] Albin, M. S., and Bunegin, L., U.S. Patent No. 4,909,069, 20 March 1990.

[2] Langdon, R. S., U.S. Patent No. 4,956,635, 11 September 1990.

[3] Leach, E. D., U.S. Patent No. 5,204,632, 20 April 1993.

[4] Dennison, E. G., Jr., U.S. Patent No. 5,036,309, 30 July 1991.

[5] Dennison, E. G., Jr., U.S. Patent No. 5,109,215, 28 April 1992.

[6] Dennison, E. G., Jr., U.S. Patent No. 5,157,379, 20 October 1992.

[7] Hermes, R. E., et al, U.S. Patent Application SN. 08/418,060, 6 April 1995.

[8] Seebode, W. F., North Hand Protection Division of Siebe North Inc., 4090 Azalea Drive, Charleston, SC, 29415. 


\section{Sixth Annual Symposium on Performance of Protective Clothing: Emerging Protection Technologies}

ASTM Committee F-23 on Protective Clothing

Session I-B: Physical Hazards

Paper ID \#: 657

\section{Protective Materials with \\ Real-Time Puncture Detection Capability}

R. E. Hermes, L. S. Valdez-Boyle, J. F. Stampfer, and D. R. Ramsey Los Alamos National Laboratory, E549, Los Alamos, NM 87545 USA 
Protective Materials with Real-Time Puncture Detection Capability

\title{
Introduction and Hindsight
}

\section{Puncture Detection at Los Alamos}

\author{
Current and Future Work
}

\author{
Other Applications
}


Protective Materials with Real-Time Puncture Detection Capability

\section{Introduction}

Protective clothing can help prevent exposure to:

- Hazardous chemicals

- Infectious biological agents

- Radioactive contamination

but due to:

- Imperfections in manufacturing

- Use in harsh environments

- Excess wear and tear and punctures 
Protective Materials with Real-Time Puncture Detection Capability

\section{Introduction (cont)}

They can:

- LEAK

Which results in:

- WORKER EXPOSURE or INJURY

- Excess reporting requirements

- Loss in productivity

- Subsequent legal action 
Protective Materials with Real-Time Puncture Detection Capability

\section{Hindsight (previous examples of leak detection devics)}

U.S. Pat. No. $4,205,672$

- Sensing circuit for wet diapers with a blinking LED.

U.S. Pat. No. $4,692,748$

- Thumbsucking deterrent uses a gloved thumb connected to an electrical circuit. 
Protective Materials with Real-Time Puncture Detection Capability

\section{Hindsight (cont)}

\section{U.S. Pat. No. 4,909,069 Mar. 20, 1990}

Method and Apparatus for Detecting Leaks in Rubber Gloves and the Like

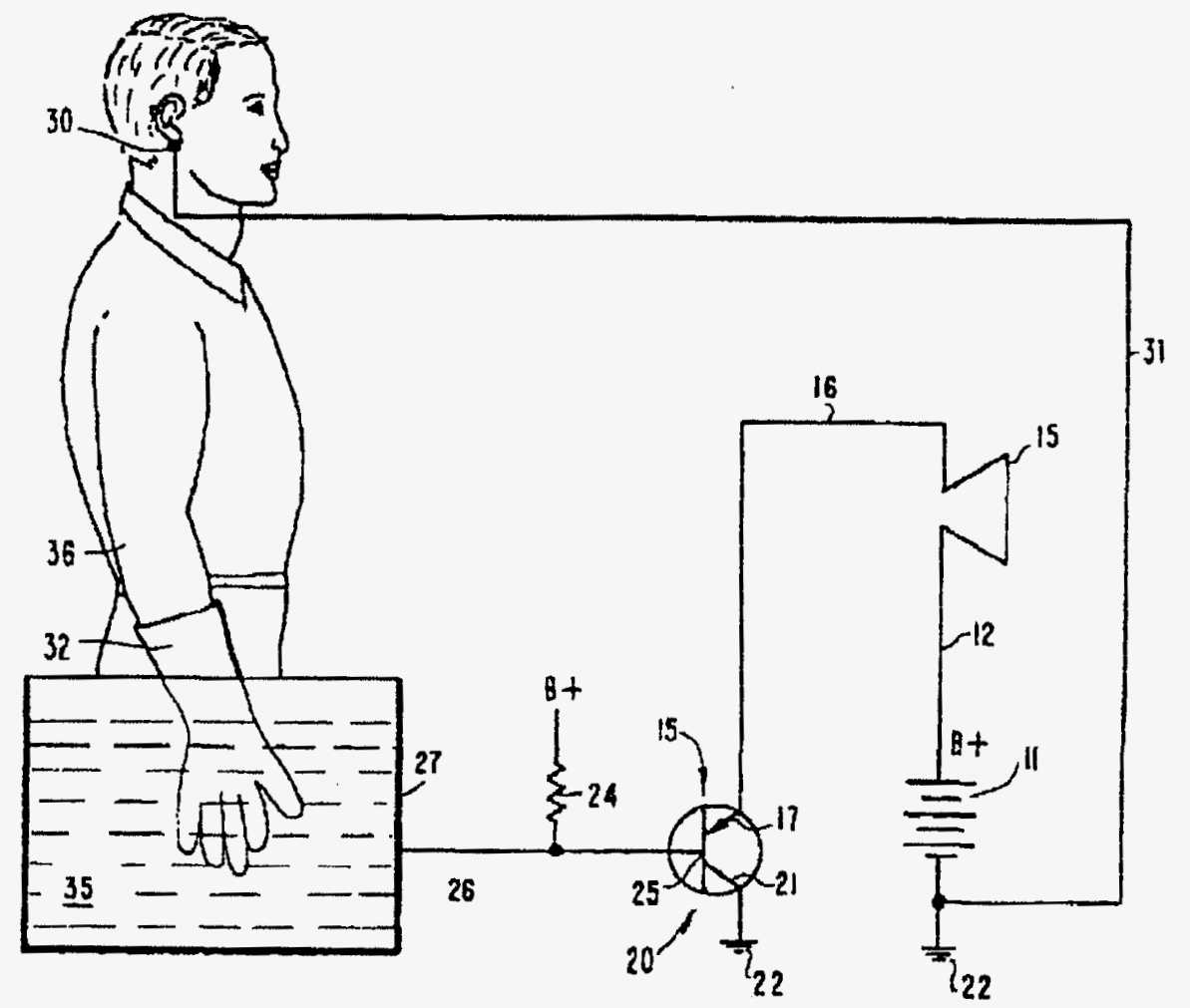


Protective Materials with Real-Time Puncture Detection Capability

\section{Hindsight (cont)}

U.S. Pat. No. 4,956,635 Sept. 11, 1990

Method and Apparatus for Testing Personal Barriers

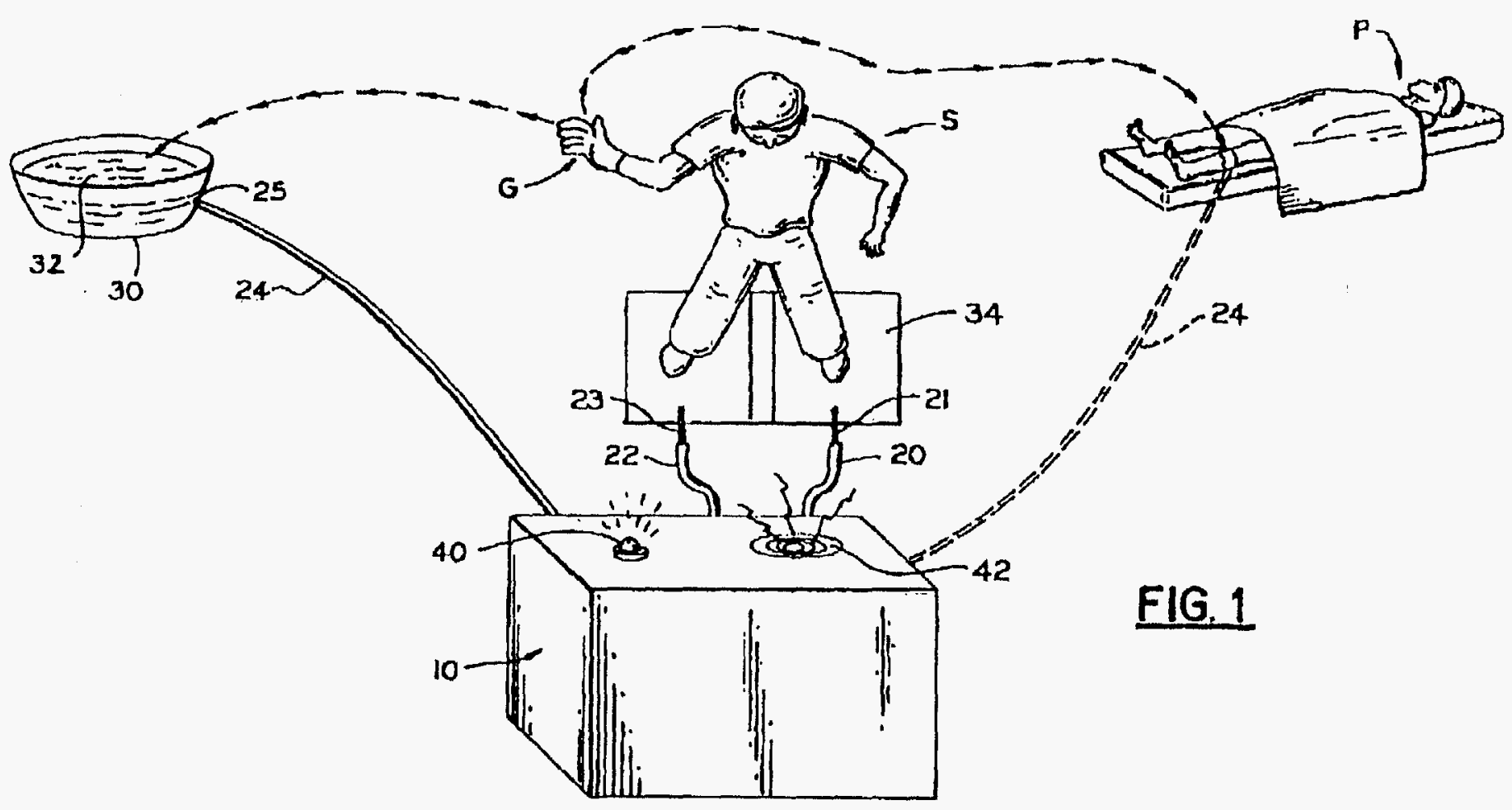


Protective Materials with Real-Time Puncture Detection Capability

\section{Hindsight (cont)}

U.S. Pat. No. 5,036,309 July 30, 1991

Portable System and Method for Continuously Monitoring Protective Clothing for Detecting and Signaling the Occurrence of a Breach Therein

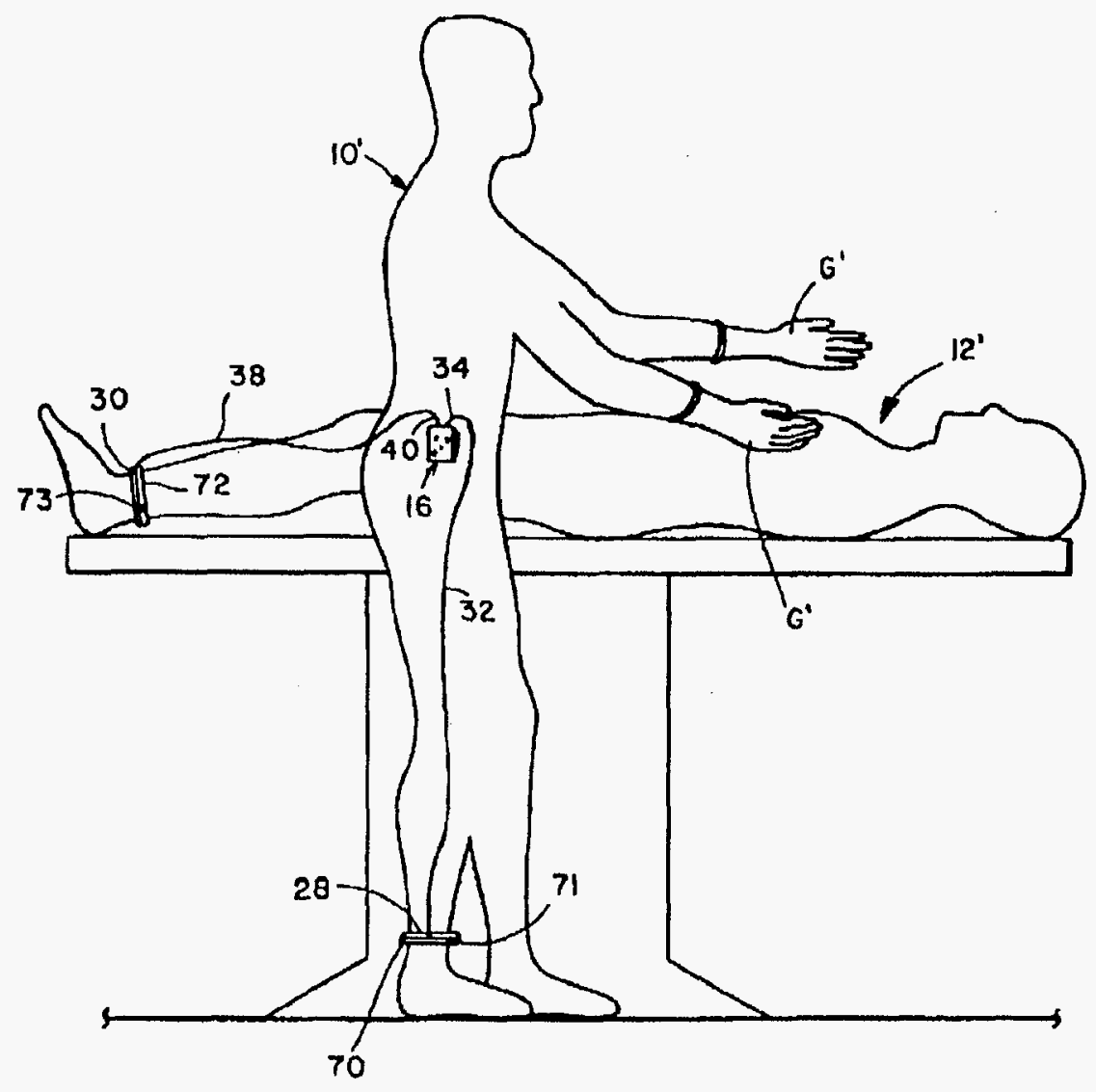

- Polymers and Coatings Group 
Protective Materials with Real-Time Puncture Detection Capability

\section{Hindsight (cont)}

U.S. Pat. No. 5,114,425 May 19, 1992

Method and Apparatus for Detecting Actual or Likely Adulteration of Critical Use Gloves

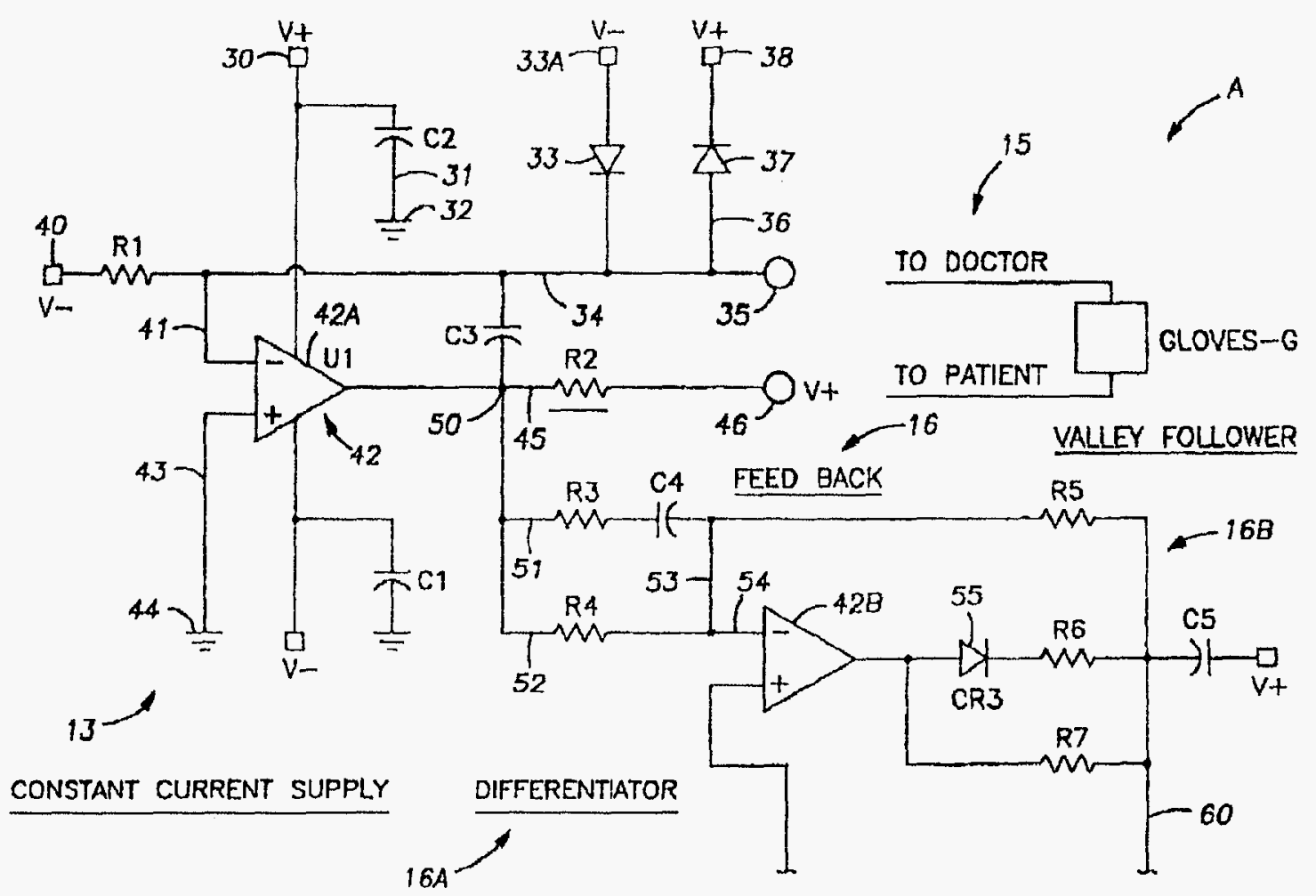


Protective Materials with Real-Time Puncture Detection Capability

\section{Hindsight (cont)}

\section{U.S. Pat. No. 5,157,379 Oct. 20, 1992}

Method for Monitoring a Protective Garment

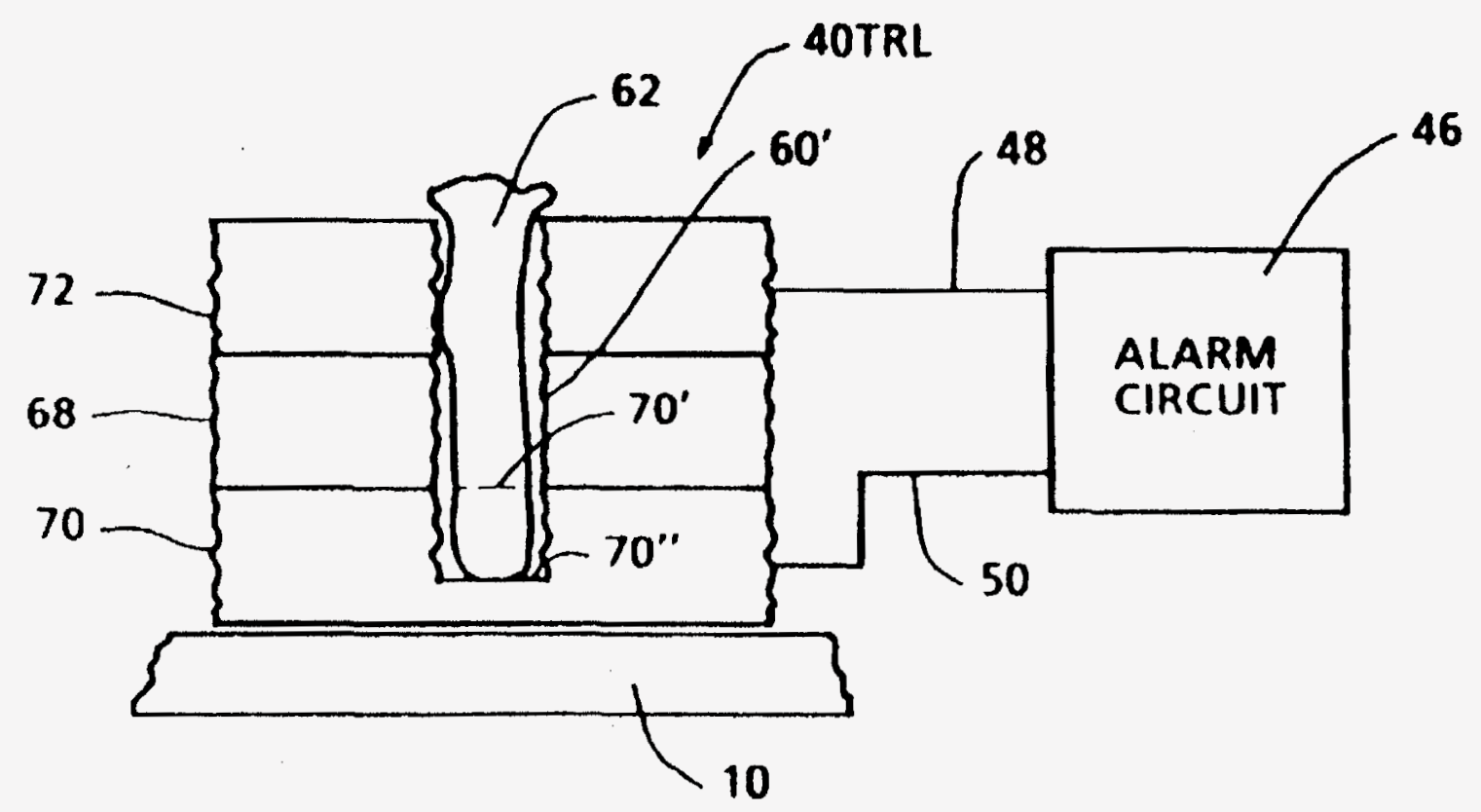

- Polymers and Coatings Group 
Protective Materials with Real-Time Puncture Detection Capability

\section{Hindsight (cont)}

U.S. Pat. No. 5,204,632 April 20, 1993

Apparatus and Method for Detecting Leaks in Surgical and Examination Gloves

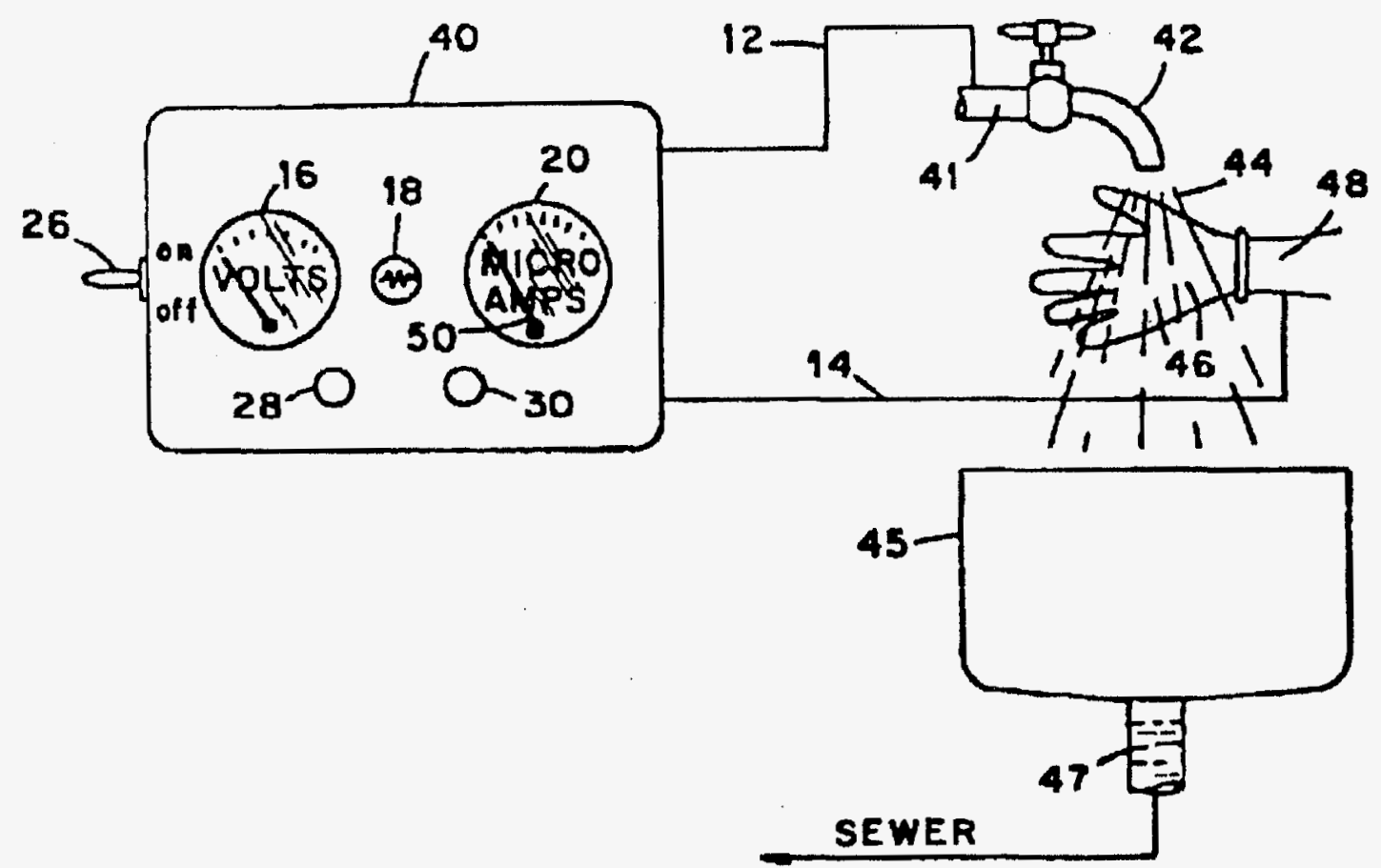

- Polymers and Coatings Group 


\section{Puncture Detection}

- Oct. 1993 - the problem

- Jan. 1994 - feasibility

- Mar. 1994 - PVA/salt prototype

- Apr. 1995 - U.S. Patent filed

- May 1995 - internal funding

- July 1995 - further developments

- Jan. 1996 - funding for gloves 
Protective Materials with Real-Time Puncture Detection Capability

\section{Puncture Detection (cont)}

U.S. Pat. Appl. No. 08/418,060

Puncture Detecting Barrier Materials

$10 \mathrm{mil}$

Hypalon $^{\mathrm{TM}}$

$15 \mathrm{mil}$

$7707 / 17$ Lead Oxide

Loaded

Neoprene $^{\mathrm{TM}}$

5 mil Hypalon $^{\mathrm{TM}}$
Apr. 6, 1995

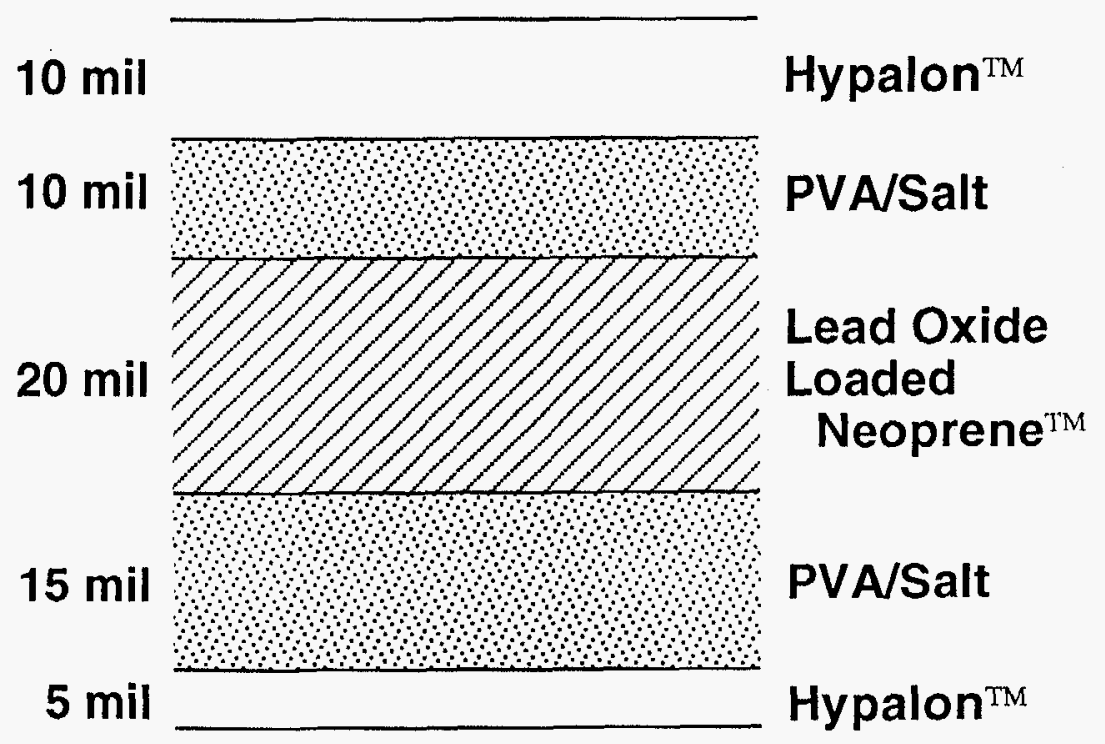

- Tested with pushpin

- Tested with wooden dowel (splinter) 
Protective Materials with Real-Time Puncture Detection Capability

\section{Materials}

- Chlorosulfonated polyethylene (layers 1 and 5)

- Lead oxide loaded polychloroprene (layer 3)

- Polyelectrolyte (layers 2 and 4)

\begin{tabular}{rlr}
$5 \%$ & Polyvinyl alcohol & $45.4 \%$ \\
$4 \%$ & Glycerol & $36.4 \%$ \\
$2 \%$ & NaCl & $18.2 \%$ \\
$89 \%$ & Water & Trace \\
\multicolumn{3}{l}{ Resistivity = 12 to 14 megohms }
\end{tabular}

- Sequential casting method 
Protective Materials with Real-Time Puncture Detection Capability

\section{Puncture Tests}

Procedure: Electrodes of layers 2 and 4 connected to DVM, with offscale reading prior to puncture test

Fresh Sample: Layer 2 or 4 is 12-14 megohms

- Metal pushpin (47 mils OD)

- 3 samples, 13 megohms average between 2 and 4

Aged Sample: Layer 2 or 4 is 30 megohms (11 months)

- Metal pushpin (47 mils OD) 1 sample, 38 megohms

- Wooden dowel (85 mils OD) 1 sample, 35 megohms 
Protective Materials with Real-Time Puncture Detection Capability

\section{Current and Future Work}

- Contract with drybox glove manufacturer

- Based on improved conductive layers

- Develop electronic testing procedure for punctures with metal, glass, and wood

- Testing with robotic manipulators

- Iteration of prototypes to improve response and strength of materials 
Protective Materials with Real-Time Puncture Detection Capability

\section{Other Applications}

- Gloves for hazardous chemical cleanup?

- Gloves for HIV, ebola, and other biohazards?

- Bodysuits for same?

- Sensor sheet for 55-gallon drums?

- Others? Please respond... 